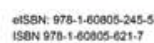

DYNAMICAL PROCESSES IN ATOMIC

AND MOLECULAR PHYSICS

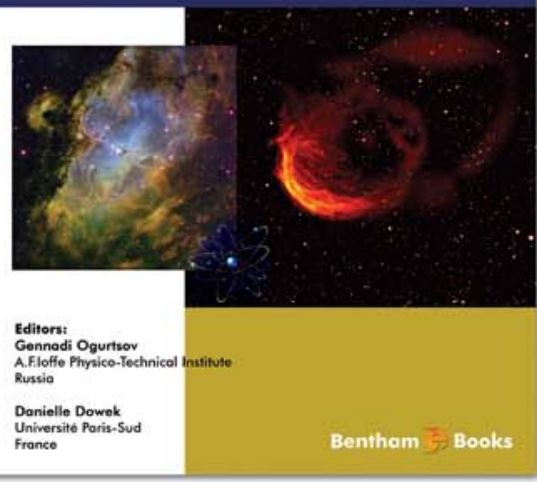

\section{Editors:}

Gennadi Ogurtsov

Russia

Danielle Dowek

France

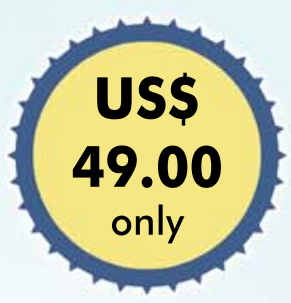

eISBN: 978-1-60805-245-5

\title{
Dynamical Processes in Atomic and Molecular Physics
}

\section{WWWhenthamseience.com/ehooks/ 9781608052455}

\section{About the ebook}

This e-book highlights the present state of investigations in the field of atomic and molecular physics. Recent theoretical developments as well as new discoveries and observations are discussed. The Book should be of interest to students studying atomic and molecular physics and specialists in related fields of science and technology.

\section{Contents}

Vortices in Atomic Processes

- Interatomic Electronic Decay Processes in Clusters

- Photoionization Dynamics: Photoemission In The Molecular Frame Of Small Molecules lonized By Linearly And Elliptically Polarized Light

Cold Molecules, Photoassociation, Optical Pumping and Laser Cooling: The Cesium Case

- Subject Index

For Sales and Advertising Inquiries: Contact: marketing@benthamscience.org 